REVIEW

\title{
Safety of neuraminidase inhibitors against novel influenza A (H1N1) in pregnant and breastfeeding women
}

\author{
Toshihiro Tanaka MD, Ken Nakajima RPh, Atsuko Murashima MD PhD, \\ Facundo Garcia-Bournissen MD, Gideon Koren MD, Shinya Ito MD
}

Published at www.cmaj.ca on June 15, 2009.

A new strain of influenza $A$ virus (novel influenza A H1N1) that originated in swine has rapidly spread from the initial outbreak in Mexico and the southern United States to Canada and many countries in Europe and Asia. Consequently, the World Health Organization raised the level of alert for an influenza pandemic to 5 on Apr. 29, 2009. ${ }^{1}$ Because many infected people are young, ${ }^{2}$ the care of pregnant and lactating women is a concern. ${ }^{3-6}$

According to the US Centers for Disease Control and Prevention, the novel H1N1 influenza virus is susceptible to oseltamivir and zanamivir, neuraminidase-inhibitor antiviral medications, which target the early phase of the infection. However, this strain is resistant to adamantanes, such as amantadine and rimantadine. ${ }^{7}$ The Centers for Disease Control and Prevention currently recommend antiviral treatment and chemoprophylaxis with either oseltamivir or zanamivir against novel H1N1 influenza for people at high risk of complications, including pregnant women., ${ }^{3,4}$

In this report, we summarize information about the safety of neuraminidase inhibitors for treatment of novel $\mathrm{H} 1 \mathrm{~N} 1$ influenza in pregnant and breastfeeding women. Although the information about drug safety in this report is also applicable to seasonal influenza and future pandemics, the management strategy presented in this article is specific to novel H1N1 influenza.

\section{Evidence}

We performed a literature search to identify reports of the use of oseltamivir or zanamivir during pregnancy, lactation and breastfeeding using MEDLINE (1950 to week 2 of May 2009) and EMBASE (1980 to week 19 of 2009) databases through the OVID system. The search terms were - pregnancy, breastfeeding, human milk, lactation, influenza, oseltamivir, and zanamivir, or their various combinations. Relevant information was also gathered through the network of teratogen information services in Japan, where the use of oseltamivir and zanamivir for patients with confirmed influenza was relatively common even before the current pandemic. ${ }^{9}$

\section{Key points}

- Pregnant women and infants are at high risk of influenzarelated complications.

- Limited data suggest that oseltamivir is not a major human teratogen.

- Because of more data about its safety in pregnancy, the use of oseltamaivir is preferred over zanamavir during pregnancy.

- Oseltamivir and zanamivir are considered to be compatible with breastfeeding.

\section{Influenza-related complications}

\section{Pregnancy}

Little is known about whether influenza viruses are transmitted to the fetus through the placenta, although this class of viruses is not considered to be teratogenic in humans. Ács and colleagues ${ }^{10}$ suggested indirect teratogenic effects of maternal influenza during pregnancy, possibly because of high fever, based on 1 case-control study and the known effects of hyperthermia, which is associated with an increased incidence of neural tube defects. ${ }^{11}$

The risk of morbidity from seasonal influenza is higher among pregnant women, ${ }^{12,13}$ especially in the third trimester, than among nonpregnant and postpartum women. ${ }^{12}$ This is consistent with increased mortality among pregnant women during past influenza pandemics. ${ }^{14,15}$ Although the novel $\mathrm{H} 1 \mathrm{~N} 1$ influenza virus may not be as virulent as anticipated, the increased risk of complications during pregnancy should be taken into account when caring for affected patients. According to the Centers for Disease Control and Prevention, 20 recent infections of novel H1N1 influenza in the United States (15 confirmed and 5 probable) were in pregnant

From the Motherisk Program, Division of Clinical Pharmacology and Toxicology, Department of Paediatrics (Tanaka, Garcia-Bournissen, Koren, Ito), The Hospital for Sick Children, University of Toronto, Toronto, Ont.; and the Japan Drug Information Institute in Pregnancy, National Center for Child Health and Development (Nakajima, Murashima), Tokyo, Japan 
Table 1: Outcomes of pregnancies in Japan after therapeutic exposure to oseltamivir in the first trimester

\begin{tabular}{|c|c|c|}
\hline Characteristic & $\begin{array}{l}\text { Toranomon Hospital }^{21} \\
n=65\end{array}$ & $\begin{array}{c}\text { Japan Drug Information Institute } \\
\text { in Pregnancy } \\
n=25\end{array}$ \\
\hline Time of exposure, gestational wk, range & $1-12$ & $2-10$ \\
\hline No. of spontaneous abortions & 1 & 2 \\
\hline No. of therapeutic abortions & 0 & 1 \\
\hline Gestational age at birth, wk, range & $35-41$ * & $35-42$ \\
\hline No. of preterm births & $2 *$ & 2 \\
\hline Birth weight, $g$, range & $2090-3810 *$ & $2418-3480$ \\
\hline No. of infants with a low birth weight & $3 *$ & 4 \\
\hline No. of infants with a major malformation & $1+$ & 0 \\
\hline
\end{tabular}

${ }^{*} n=42$ (women exposed between gestational week 4 and 7 who had a live birth).

tVentricular septal defect.

women. Of the 13 women for whom sufficient data were available, 3 were admitted to hospital; 1 of these patients died of respiratory complications. This patient was started on oseltamivir therapy 1 week after acute respiratory distress developed. ${ }^{6}$ At present, the groups at high risk of influenzarelated complications from the novel H1N1 influenza are the same as those for seasonal influenza. These groups include, but are not limited to, pregnant women and children aged 5 years or less. ${ }^{8}$

\section{Lactation}

Whether influenza viruses are passed into human milk is not known; however, respiratory droplets are likely to be the main mode of viral transmission. Because of the anti-infective benefits of human milk for infants, continuation of breastfeeding is recommended even if the mother is receiving treatment for novel H1N1 influenza infection. ${ }^{3-5}$

\section{Pharmacotherapy}

The Centers for Disease Control and Prevention recommendation $^{8}$ during the current pandemic is that drug treatment and chemoprophylaxis be considered, along with other public health measures, for patients at high risk of complications, including pregnant women and infants. Recent meta-analyses have suggested that oseltamivir and zanamivir may be modestly effective in alleviating symptoms of seasonal influenza in otherwise healthy adults ${ }^{16}$ and children. ${ }^{17}$ Routine use of these drugs is discouraged for patients at low-risk of complications from seasonal influenza, although these neuraminidase inhibitors are capable of reducing withinhousehold spread of the disease, nasal viral load and lower respiratory tract complications. ${ }^{16}$ Data about the effectiveness of these drugs in high-risk populations, specifically during the current pandemic, are limited.

\section{Oseltamivir}

Oseltamivir is a prodrug that is hydrolyzed by the liver to its active metabolite, oseltamivir carboxylate, with an elim- ination half-life of about 6-10 hours. ${ }^{18}$ The therapeutic oral dosage for influenza, including novel H1N1 influenza, for adults is $75 \mathrm{mg}$ taken twice daily for 5 days, starting within 48 hours of the initial symptoms to capture the early phase of viral replication. For chemoprophylaxis, the recommended dosage is $75 \mathrm{mg}$ taken once daily for 10 days after exposure. ${ }^{8}$ Therapeutic and prophylactic dosing schedules for children are similar (about $2 \mathrm{mg} / \mathrm{kg}$ twice a day for 5 days for treatment, and $2 \mathrm{mg} / \mathrm{kg}$ once a day for 10 days for prophylaxis). ${ }^{8}$

\section{Pregnancy}

A study using an ex vivo human placenta model showed that oseltamivir was extensively metabolized by the placenta. ${ }^{19}$ Transplacental transfer of the metabolite was incomplete with minimal accumulation on the fetal side. ${ }^{19}$ In postmarketing surveillance, 61 pregnant women who were exposed to oseltamivir with unknown timing were reported by the manufacturer. ${ }^{20}$ Among these pregnancies, there were 10 abortions, including 6 therapeutic terminations, and 1 case each of trisomy 21 and anencephaly. ${ }^{20}$ These findings are consistent with data from 2 Japanese teratogen information services (Toranomon Hospital, ${ }^{21}$ and Japan Drug Information Institute in Pregnancy, National Center for Child Health and Development, Tokyo, Japan), which prospectively followed 90 pregnant women who took therapeutic doses of oseltamivir (75 mg twice a day for up to 5 days) during the first trimester (Table 1). In these 90 cases, there was 1 malformation $(1.1 \%)$, which is within the incidence of major malformations in general population $(1 \%-3 \%)$.

\section{Lactation}

Wentges-van Holthe and colleagues ${ }^{22}$ reported the case of a lactating woman who received oseltamivir ( $75 \mathrm{mg}$ twice daily for 5 days). The maximum milk concentrations of oseltamivir and its active metabolite were $38.2 \mathrm{ng} / \mathrm{mL}$ and $39.5 \mathrm{ng} / \mathrm{mL}$ (equivalent to $43.4 \mathrm{ng} / \mathrm{mL}$ of oseltamivir), respectively. The authors estimated that the infant would have been exposed to milk containing a maximum of $81.6 \mathrm{ng} / \mathrm{mL}$ oseltamivir- 
equivalents, which corresponds to $0.012 \mathrm{mg} / \mathrm{kg}$ per day. ${ }^{22}$ This is much smaller than the pediatric doses $(2-4 \mathrm{mg} / \mathrm{kg}$ per day).

\section{Zanamivir}

Zanamivir is administered by inhalation with a dry powder inhaler. The bioavailability of the drug is $10 \%-20 \%$ by inhalation, compared with $2 \%$ by oral administration. About $90 \%$ of the absorbed dose is excreted unchanged in the urine. The elimination half-life in serum of zanamivir is between 2.5 and 5.1 hours. ${ }^{23}$ The therapeutic dose is $10 \mathrm{mg}$ inhaled twice daily for 5 days starting within 48 hours of the initial symptoms. For chemoprophylaxis, the dose is once daily for 10 days after exposure. ${ }^{78}$ The recommended doses for children are the same. ${ }^{8}$ Because zanamivir therapy requires the patient to voluntarily inhale through the device, oseltamivir may be preferred over zanamivir for young children.

\section{Pregnancy}

Three pregnant women were accidentally exposed to zanamivir during clinical trials. ${ }^{24}$ Among these women, 1 pregnancy was spontaneously miscarried, 1 pregnancy was terminated, and 1 woman delivered a healthy baby. ${ }^{24}$ The Japan Drug Information Institute in Pregnancy has information about 1 woman who took zanamivir at 4 weeks of gestation and delivered a healthy baby at term.

\section{Lactation}

A peak concentration of zanamivir in the serum after a $10 \mathrm{mg}$ oral-inhalation dose ranges from 34 to $96 \mathrm{ng} / \mathrm{mL} .^{23}$ Assuming a maternal serum concentration of $100 \mathrm{ng} / \mathrm{mL}$, a milk-toplasma ratio of 1.0 and an intake of milk of $150 \mathrm{~mL} / \mathrm{kg}$ per day, the maximum amount of zanamivir that a $5 \mathrm{~kg}$ infant would ingest would be about $0.075 \mathrm{mg} / \mathrm{day}$, which is much lower than the recommended prophylactic dosage for children of $10 \mathrm{mg} /$ day inhalation.

\section{Vaccine}

The seasonal influenza vaccine does not appear to provide protection against novel H1N1 influenza. ${ }^{25}$ Currently no vaccine for novel H1N1 influenza exists. However, vaccination for seasonal influenza should continue because of higher morbidity among pregnant women and possible concurrent epidemics with novel H1N1 influenza. ${ }^{26}$ Once developed, it is unlikely that an inactivated vaccine against novel H1N1 influenza would be contraindicated for pregnant and lactating women, similar to regular influenza vaccines. ${ }^{27,28}$

\section{Discussion}

Pregnant women, especially those in the late stages of pregnancy, are at high risk of complications from influenza, including novel H1N1 influenza. Although the data are limited, this should be considered during the current novel H1N1 influenza pandemic.

If treatment or chemoprophylaxis is required for pregnant women during the current pandemic, oseltamivir appears to be the drug of choice because there are more data on its safety in pregnancy. The data suggest that oseltamivir is not a major teratogen for humans. Zanamivir may also be used, but there are less data available about its safety for pregnant women.

Both oseltamivir and zanamivir are considered to be compatible with breastfeeding. Continuation of breastfeeding by a woman taking these medications is unlikely to lead to substantial drug exposure by the infant. Adjustment of dose because of breastfeeding is not necessary. If mother-infant contact is clinically allowed, breastfeeding during oseltamivir or zanamivir treatment is acceptable. If an infant being breastfed by the mother receiving oseltamivir or zanamivir needs direct treatment or chemoprophylaxis, the recommended dose of oseltamivir or zanamivir for infants should be given. Therapy should start within 48 hours of the initial symptoms.

Prospective data collection with robust follow-up should continue for both oseltmivir and zanamivir.

This article has been peer reviewed.

Competing interests: None declared.

Contributors: Toshihiro Tanaka conceived and initiated this project, searched the literature, collected information, and drafted and revised the manuscript. Ken Nakajima searched Japanese literature, analyzed and interpreted the follow-up data collected from the Japan Drug Information Institute in Pregnancy, and drafted the paper. Atsuko Murashima critically interpreted the follow-up data collected from Japan Drug Information Institute in Pregnancy and drafted the paper. Facundo Garcia-Bournissen conceived the project, searched the Spanish literature, provided critical interpretation of the collected information and critically revised the draft. Gideon Koren provided critical interpretation of the data and revised the manuscript for key content. Shinya Ito searched literature, provided critical interpretation of the data, drafted the paper and revised it critically. All of the authors approved the final version submitted for publication.

Acknowledgements: Dr. Tanaka is supported by Nobel Pharma Scholarship, TFB Scholarship, Scholarship for Researchers through the Japanese Society of Clinical Pharmacology and Therapeutics, and The Research and Training Competition (RESTRACOMP) through the Hospital for Sick Children Research Institute.

Dr. Garcia-Bournissen has received funding from the Clinician Scientist Training Program. This program is funded by the Ontario Student Opportunity Trust Fund and the Hospital for Sick Children Foundation Student Scholarship Program.

Dr. Koren is the Ivey Chair in Molecular Toxicology, Department of Medicine, University of Western Ontario, and he holds the Research Leadership for Better Pharmacotherapy during Pregnancy and Lactation at The Hospital for Sick Children, Toronto, Ont.

Funding: The Japan Drug Information Institute in Pregnancy is supported by the Japanese Ministry of Health, Labor and Welfare. This report is supported by the National Center for Child Health and Development-Motherisk Collaborative Research Fund.

\section{REFERENCES}

1. Chan M. Influenza A (H1N1). Geneva (Switzerland): World Health Organization; 2009. Available: www.who.int/mediacentre/news/statements/2009/h1n1 20090429/en/index.html (accessed 2009 May 27).

2. Centers for Disease Control and Prevention. Update: novel influenza A (H1N1) virus infections — worldwide, May 6, 2009. MMWR Morb Mortal Wkly Rep 2009;58:453-8.

3. Centers for Disease Control and Prevention. Pregnant women and novel influenza A (H1N1) considerations for clinicians. Atlanta (GA): The Centers; 2009. Available: www.cdc.gov/h1n1flu/clinician_pregnant.htm (accessed 2009 May 27).

4. Centers for Disease Control and Prevention. What pregnant women should know about H1N1 (formerly called swine flu) virus. Atlanta (GA): The Centers; 2009. Available: www.cdc.gov/h1n1flu/guidance/pregnant.htm (accessed 2009 May 27).

5. Centers for Disease Control and Prevention. Novel H1N1 flu (swine flu) and feeding your baby: what parents should know. Atlanta (GA): The Centers; 2009. Available: www.cdc.gov/h1n1flu/breastfeeding.htm (accessed 2009 May 27). 
6. Centers for Disease Control and Prevention. Novel influenza A (H1N1) virus infections in three pregnant women — United States, April-May 2009. MMWR Morb Mortal Wkly Rep 2009;58:497-500.

7. Centers for Disease Control and Prevention. Update: drug susceptibility of swineorigin influenza A (H1N1) viruses, April 2009. MMWR Morb Mortal Wkly Rep 2009;58:433-5.

8. Centers for Disease Control and Prevention. Interim guidance on antiviral recommendations for patients with novel influenza A (H1N1) virus infection and their close contacts. Atlanta (GA): The Centers; 2009. Available: www.cdc.gov/h1n1flu /recommendations.htm (accessed 2009 May 17).

9. Hata K, Koseki K, Yamaguchi K, et al. Limited inhibitory effects of oseltamivir and zanamivir on human sialidases. Antimicrob Agents Chemother 2008;52:3484-91.

10. Ács N, Banhidy F, Puho E, et al. Maternal influenza during pregnancy and risk of congenital abnormalities in offspring. Birth Defects Res A Clin Mol Teratol 2005; 73:989-96.

11. Moretti ME, Bar-Oz B, Fried S, et al. Maternal hyperthermia and the risk for neural tube defects in offspring: systematic review and meta-analysis. Epidemiolog 2005;16:216-9.

12. Neuzil KM, Reed GW, Mitchel EF, et al. Impact of influenza on acute cardiopulmonary hospitalizations in pregnant women. Am J Epidemiol 1998;148:1094-102.

13. Dodds L, McNeil SA, Fell DB, et al. Impact of influenza exposure on rates of hospital admissions and physician visits because of respiratory illness among pregnant women. CMAJ 2007;176:463-8.

14. Harris JW. Influenza occurring in pregnant women: a statistical study of thirteen hundred and fifty cases. JAMA 1919;72:978-80.

15. Freeman DW, Barno A. Deaths from Asian influenza associated with pregnancy. Am J Obstet Gynecol 1959;78:1172-5.

16. Jefferson TO, Demicheli V, Di Pietrantonj C, et al. Neuraminidase inhibitors for preventing and treating influenza in healthy adults. Cochrane Database Syst Rev 2006;(3):CD001265

17. Matheson NJ, Harnden A, Perera R, et al. Neuraminidase inhibitors for preventing and treating influenza in children. Cochrane Database Syst Rev 2007;(1): CD002744.

18. He G, Massarella J, Ward P. Clinical pharmacokinetics of the prodrug oseltamivir and its active metabolite Ro 64-0802. Clin Pharmacokinet 1999;37:471-84.
19. Worley KC, Roberts SW, Bawdon RE. The metabolism and transplacental transfer of oseltamivir in the ex vivo human model. Infect Dis Obstet Gynecol 2008;2008: 927574

20. Ward P, Small I, Smith J, et al. Oseltamivir (Tamiflu) and its potential for use in the event of an influenza pandemic. J Antimicrob Chemother 2005;55(Suppl 1):i5-21.

21. Hayashi M, Yamane R, Tanaka M, et al. Pregnancy outcome after maternal exposure to oseltamivir phosphate during the first trimester: a case series survey [Japanese]. Nihon Byoin Yakuzaishi Gakkai Zasshi 2009;45:547-50.

22. Wentges-van Holthe N, van Eijkeren M, van der Laan JW. Oseltamivir and breastfeeding. Int J Infect Dis 2008;12:451.

23. Cass LM, Efthymiopoulos C, Bye A. Pharmacokinetics of zanamivir after intravenous, oral, inhaled or intranasal administration to healthy volunteers. Clin Pharmacokinet 1999;36(Suppl 1):1-11.

24. Freund B, Gravenstein S, Elliott M, et al. Zanamivir: a review of clinical safety. Drug Saf 1999;21:267-81.

25. Centers for Disease Control and Prevention. Serum cross-reactive antibody response to a novel influenza A (H1N1) virus after vaccination with seasonal influenza vaccine. MMWR Morb Mortal Wkly Rep 2009;58:521-4.

26. Pan American Health Organization. EOC situation report \#7: influenza A/H1N1 in the Americas (Mexico, the United States, Canada). Geneva (Switzerland): The Organization; 2009. Available: new.paho.org/hq/index.php?option=com_content\& task=view\&id=1290\&Itemid $=569$ (accessed 2009 May 27).

27. Fiore AE, Shay DK, Broder K, et al. Prevention and control of influenza: recommendations of the Advisory Committee on Immunization Practices (ACIP), 2008. MMWR Morb Mortal Wkly Rep 2008;57(RR-7):1-60.

28. ACOG Committee on Obstetric Practice. ACOG committee opinion number 305 , November 2004. Influenza vaccination and treatment during pregnancy. Obste Gynecol 2004;104(5 Pt 1):1125-6.

Correspondence to: Dr. Shinya Ito, Division of Clinical

Pharmacology and Toxicology, Department of Paediatrics, The

Hospital for Sick Children, 555 University Ave., Toronto ON

M5G 1X8; fax 416 813-7562; shinya.ito@sickkids.ca

\section{$+$ Health Santé
Canada $\begin{array}{ll}\begin{array}{l}\text { Your health and } \\ \text { safety...our priority. }\end{array} & \begin{array}{l}\text { Votre santé et votre } \\ \text { sécurité... notre priorité. }\end{array}\end{array}$}

Canadian Adverse Reaction Newsletter Highlights from the July 2009 issue of Health Canada's Canadian Adverse Reaction Newsletter.

- $\quad$ Montelukast (Singulair): psychiatric reactions

- Intravitreal injection of triamcinolone acetonide: ocular reactions

- Fentanyl transdermal patches and accidental child exposure

- Quarterly summary of advisories

Visit the MedEffect ${ }^{\mathrm{TM}}$ Canada Web site at

www.healthcanada.gc.ca/medeffect to view or to subscribe for free to the Newsletter and other

health products advisories.

\section{\begin{tabular}{|llll} 
Santé & $\begin{array}{l}\text { Health } \\
\text { Canada }\end{array}$ & $\begin{array}{l}\text { Votre santé et votre } \\
\text { sécurité... notre priorité. }\end{array}$ & $\begin{array}{l}\text { Your health and } \\
\text { safety...our priority. }\end{array}$
\end{tabular}}

Bulletin canadien des effets indésirables

Les grandes lignes du numéro de juillet 2009 du Bulletin canadien des effets indésirables de Santé Canada.

- Montélukast (Singulair) : effets indésirables psychiatriques

- Injection intravitréenne de triamcinolone acétonide et effets oculaires

- Timbres transdermiques de fentanyl et exposition accidentelle chez l'enfant

- Sommaire trimestriel des avis

Visitez le site Web MedEffet ${ }^{\mathrm{MC}}$ Canada à www.santecanada.gc.ca/medeffet pour consulter ou vous abonner gratuitement au Bulletin et aux avis sur les produits de santé. 